\title{
Psychological Predictors of Obesity
}

\author{
Urbi Mukherjee $^{1 *}$, Bidita Bhattacharya ${ }^{2}$, Dr. Shikha Mukhopadhyay ${ }^{3}$, \\ Shuvabrata Poddar ${ }^{4}$
}

\section{ABSTRACT}

Objectives: Obesity is now fast growing, major public health concern in many countries worldwide, including India. Predictors of obesity range from biological, behavioral factors to socioeconomic and contextual factors. Studies of personality as a psychological predictor of obesity are scarce and contradictory so the present study aimed to assess whether personality can predict obesity or not. Methods: A sample of 60 individuals within the age group 18-40years (mean=25.73 \pm 2.86 ) was selected using purposive sampling, divided into obese and non-obese groups on the basis of Body Mass Index (BMI), with 30 individuals in each group. The sample was assessed on the basis of NEO Five Factor Inventory (McCrae \& Costa, 1991) and SelfConcept Inventory (Shah, 1986). Logistic regression and t-test were computed. Results: The two groups differed significantly in the various domains of personality and self concept. Personality traits of Openness (O), Extraversion (E) and emotional, cognitive and political self concept were found to be major predictors of obesity. Conclusions: The findings indicate psychological traits are connected to the evolution of obesity. This makes necessary to assess and consider such psychological aspects for the appropriate treatment of such patients.

Keywords: Obesity, Personality, Predictor, Self- concept.

Over the past 40 years, obesity has been increasing at an alarming rate throughout the world with diverse patterns across nations and ethnic populations. It is a complex, multifactorial disease that develops from the interaction between genotype and the environment characterized by excessive amount of body weight. Researchers found that obesity was the sixth most important risk factor contributing to the overall burden of disease worldwide (Haslam \& James, 2005).The World Health Organization (WHO) definition of overweight and obesity denotes

\footnotetext{
${ }^{1}$ Assistant Professor, Department of Psychology, Department of Psychology, Dr. APJ Abdul Kalam Government Degree College, West Bengal State University

${ }^{2}$ Head \& Assistant Professor, Department of Clinical Psychology, Institute of Psychiatry

${ }^{3}$ Associate Professor, Department of Psychiatry, Institute of Psychiatry

${ }^{4}$ Assistant Professor, Department of Applied Psychology, Kazi Nazrul University

*Responding Author

(C) 2016 I U Mukherjee, B Bhattacharya, S Mukhopadhyay, S Poddar; licensee IJIP. This is an Open Access Research distributed under the terms of the Creative Commons Attribution License (http://creativecommons.org/licenses/by/2.0), which permits unrestricted use, distribution, and reproduction in any Medium, provided the original work is properly cited.
} 


\section{Psychological Predictors of Obesity}

abnormal or excessive fat accumulation that may impair health (WHO, 2010). The Centers for Disease Control define overweight and obesity as "labels for ranges of weight that are greater than what is generally considered healthy for a given height" (Centers for Disease Control, CDC, 2006).

Broadly, obesity is classified into primary and secondary. Primary obesity,or simple or alimentary obesity, happens when a person consumes more kilojoules than the body can utilize, and accounts for approximately 95\% of obesity cases. Secondary obesity occurs as a consequence of some disease and which disappears after the disease has been cured.

The most widely used definitions of obesity are based on Body Mass Index (BMI), which is calculated as weight in kilograms divided by the square of height in meters $\left(\mathrm{kg} / \mathrm{m}^{2}\right)$. A BMI of 30 $\mathrm{kg} / \mathrm{m}^{2}$ is widely recognized as a cut-off point for obesity. It provides a simple and the most useful population level measure of obesity in adults. Given the small body frame of Indians and other Asians, data suggest that the proposed cut-offs by WHO for defining overweight and obesity are not appropriate for Asian Indians, and that they are at risk of developing obesity related comorbidities at lower levels of BMI and waist circumference. In particular, in some Asian populations a specific BMI reflects a higher percentage of body fat than in white or European populations.

The Indian Ministry of Health and Family Welfare proposed new obesity guidelines, which, in light of the particularly susceptibility of Indians to weight-related health problems, reduced the body-mass-index criteria for the diagnosis of overweight and obesity in Indians to 23 and 25 $\mathrm{kg} / \mathrm{m}^{2}$ respectively (Misra et al., 2009). Data indicates that $15 \%$ of the Indian population has obesity (Misra et al., 2009).The rise in the prevalence of overweight and obesity in many lowerand middle-income countries in the Asia-Pacific region is regarded as a negative consequence of the economic development (Asia Pacific Cohort Studies, 2007).

Arguing that obesity results from overindulgence of food or lack of physical activity is an oversimplification. Among the numerous efforts invested on obesity research, some determinants of obesity have been identified at both macro and micro levels, ranging from biological, behavioral factors to socioeconomic and contextual factors. It is now considered as an important topic under Behavioural Medicine. Behavioural determinants of obesity may be conditioned by either genetic or social factors. They are believed to be important proximate factors in obesity, and are taken as the pathway of distal social determinants in affecting the obesity outcome. In particular, personality traits are consistently associated with the controllable behaviors that lead to obesity (Provencher et al., 2008) and personality has an effect on adiposity even after controlling for known demographic and genetic influences (Terracciano et al., 2009). This line of evidence suggests that weight is a physical manifestation of processes inherent to an individual's characteristic ways of thinking, feeling, and behaving. Thus, body weight is, in part, a reflection of the processes that define common personality traits. Overweight individuals have ascribed traits based on their body size (Roehling et al., 2008). In fact, just being associated with someone 
who is overweight can lead to negative evaluations (Hebl \& Mannix, 2003). As such, body weight contributes to how we understand ourselves, how we see others, and how others see us. Thus existing body of literature clearly suggests that obesity has its source rooted in the personality of individuals, while at the same time the psychological point of view acknowledge the role and importance of other organic and societal factors.

However, published research work on the core psychological components in relation to obesity in Indian adults is sparse. The present study is an attempt to probe into the issue from some selected aspects of personality. The selected variables of the study are as follows:

\section{Personality:}

Ever since the early work of Sir Francis Galton, psychologists have searched for just a small number of dispositions or traits to describe the human personality. Digman (1990) claimed that there had been a significant amount of literature over the past 50 years which had suggested that there were five main factors of personality. The five factor model of personality, largely developed by Costa and McCrae $(1985,1989,1990)$ represents the structure of traits reflecting the most basic dimensions: Neuroticism (N), Extraversion (E), Openness (O), Agreeableness (A) and Conscientiousness (C). Neurotic individuals are characterized by moody, touchy, anxious and restless. Extraversion refers to the tendency to seek company of other people, to like talking to other people, and to gain pleasure and enjoyment from being with other people. Openness concerns with being open to experience, including traits of creative, daring, independent and artistic. Agreeableness includes the traits good-natured, helpful, trusting and lenient. Conscientiousness includes the traits careful, self-reliant, scrupulous and knowledgeable.

Numerous studies (Booth-Kewley\& Vickers, 1994) found that among these five traits, conscientiousness had the strongest relationship with people's healthy eating behaviour- when the other four traits were controlled, the conscientiousness level remained significant in predicting people's healthy eating behaviours, whereas the other four traits were less potent predictors of health behaviours. Similar findings demonstrated that people with high conscientiousness level tended to have healthier eating behaviours and attitudes than people with low conscientiousness level, regardless of the environment in which they reside (Hong, 2013). Magee and Heaven (2011) reported that Extraversion, Agreeableness and Neuroticism were cross-sectionally associated with obesity, with Conscientiousness inversely associated with obesity. Elfhag and Morey (2008) found that eating was strongly positively associated to Neuroticism, in particular impulsiveness and depression, and further linked to lower Conscientiousness mainly seen in lower self-discipline, and lower Extraversion. External eating was likewise mainly associated to the facets impulsiveness and lower self-discipline. Restrained eating was on the other hand related to higher Conscientiousness, Extraversion and Openness, and lower Neuroticism. Average BMI levels during midlife were positively related to Neuroticism and negatively related to Openness, Agreeableness, and Conscientiousness. The relation between Conscientiousness and BMI was significant in males and females, however, the 
magnitude of the negative association was stronger in females. Conscientiousness also predicted change in BMI during midlife such that participants who were lower in Conscientiousness tended to show larger gains in BMI with age (Day et al., 2005; Brummett et al., 2006). Kakizaki et al. (2008), using Eysenck Personality Questionnaire-Revised version, short form found that in men and women, extraversion and psychoticism had positive associations with overweight, whereas neuroticism had an inverse association. In another study multilevel linear regression analysis was used to assess the contribution of personality variables measured by Minnesota Multiphasic Personality Inventory-2 (MMPI-2) to the prediction of variance in obese range BMI, where Hypomania and Psychopathic Deviate emerged as statistically significant predictors of BMI (Valenti, 2011).

\section{Self-Concept:}

Self-concept refers to a set of self-identities and self-schemas that, together, form the person we perceive ourselves to be (Wakslak et al., 2008). By enabling us to define who we are, a selfconcept is central to our existence as human beings: it shapes our thoughts and actions, it serves as a lens through which we interpret the environment and our experiences, and it drives us to behave with some consistency across a variety of situations. According to Rosenberg (1979), self-concept is the individual's fundamental frame of reference that includes almost all actions that are predicated. As early as 1902, Cooley related immediate social reality to self expanding his theme in social organization and self-, social- and public- consciousness. As an intricate combination of distinct self-identities and self-schemas that vary along a multitude of dimensions, the self-concept is a difficult construct to research, as only a small subset of the many aspects of self-concept may be afforded at a particular point in time (Shah, 1986).

Studies on self-concept in relation with obesity mostly comprised children and adolescents sample in American-African, Chinese and Indian population (Witherspoon et al., 2013; Lau et al., 2008; Rashmi \& Jaswal, 2010). Body-image studies among adults are commonly found but there is dearth of studies concerning self-concept of adult obese individuals.

The specific objectives of the present study are as follows:

- To assess and compare between obese and non-obese adults along the dimensions of personality and self-concept.

- To predict the different psychological variables (in terms of personality and self concept) associated with obesity.

\section{MATERIAL AND METHODS}

\section{Participants:}

A sample of 60 individuals within the age group 18-40years (mean=25.73 \pm 2.86 ), having minimum eight years of formal education, Indian citizens, not suffering from any organic disease, endocrinological disorder (thyroidism and Cushing syndrome), neurological disorder, terminal illness, mental retardation and psychiatric disorders was selected using purposive 
sampling method. They were classified into obese (BMI $\geq 25 \mathrm{~kg} / \mathrm{m}^{2}$ ) and non-obese groups on the basis of Body Mass Index (BMI), with 30 individuals in each group (Comparable group- 1 and Comparable group- 2 respectively). The two groups were matched in terms of age, sex and educational qualification. Presence of any sort of psychiatric morbidity in Comparable group- 2 was ruled out using appropriate screening tool.

The sample was assessed on the basis of NEO Five Factor Inventory (McCrae \& Costa, 1991) and Self-Concept Inventory (Shah, 1986). Logistic regression and t-test were computed.

\section{Research design:}

The study followed cross-sectional hospital-based study design using purposive sampling method.

The variables under investigation were- Personality traits and Self-concept.

\section{Measures:}

Semi-structured socio-demographic datasheet: This was used to collect the background information about the participants such as the name, address, age, sex, educational qualification, marital status, occupation, family type, family income, current height and weight, health status and family history of endocrinological disorders.

General Health Questionnaire-28 [GHQ-28; Goldberg \& Miller, 1979]: This 28-item questionnaire was used as a screening test to rule out presence of psychiatric morbidity in Comparable group 2. Each of the items has four response alternatives. The split half reliability is 0.97 .

NEO Five Factor Inventory (McCrae \& Costa, 1991): It is a 60-item version of Form S of the Revised NEO Personality Inventory that provides a brief, comprehensive measure of the five domains of personality, namely, Neuroticism (N), Extraversion (E), Openness (O), Agreeableness (A), Conscientiousness (C). It consists of five 12-item scales that measure each domain on a five-point scale- 'Strongly disagree', 'Disagree', 'Neutral', 'Agree', 'Strongly agree'. Higher the score higher would be the orientation in respective dimensions. The reliability coefficients across domains range between 0.79 and 0.83 (Costa \& McCrae, 1991).

Self Concept Inventory (Shah, 1986): This inventory consists 64 items (adjectives) related to 10 content categories (social, emotional, physical, cognitive, aesthetic, political, jobrelated, Self-confidence, Self-concept related to beliefs and traditions and Self-concept related to Personality Traits)of self were arranged randomly. Summation of all items would give the measure of Composite Self-Concept. Higher score indicates positive association with good self-concept (Shah, 1986). The reliability coefficients for different dimensions as well as for the Composite Self-Concept range between 0.58 and 0.82 . The significant correlation coefficient between the dimensions of self-concept, and between composite score and dimensions $(\mathrm{p}<0.001)$ indicates satisfactorily high validity of the inventory (Shah, 1986). 


\section{Psychological Predictors of Obesity}

\section{Procedure}

Participants meeting inclusion criteria were first interviewed followed by initial assessment of height, weight and calculation of Body Mass Index (BMI) using the formula: weight in kilograms divided by the square of height in meters $\left(\mathrm{kg} / \mathrm{m}^{2}\right)$.

Individuals' whose $\mathrm{BMI} \geq 25 \mathrm{~kg} / \mathrm{m}^{2}$ and whose age and education level matched with the inclusion criteria were further inquired. They were informed about the research purpose, followed by taking informed consent from them. Maintenance of confidentiality of information was assured.

The socio-demographic details of the individuals were then collected using socio-demographic datasheet. Previous medical history and medical report were clarified and checked to rule out presence of organic disease, endocrinological disorders, (thyroidism, diabetes, Cushing syndrome) and pituitary malfunctions and other secondary obesity. If in doubt, physicians' help was sought to fulfil exclusion criteria. Further screening was done through General Health Questionnaire-28 [GHQ-28; Goldberg \& Miller, 1979]. Adult individuals who scored less than 4 in GHQ, were then provided with Self Concept Inventory (Shah, 1986), NEO Five Factor Inventory (McCrae \& Costa, 1991). Control group subjects were selected from Institute of Psychiatry outpatient department (non-relative accompanying person with the patient) and few offices and academic institutes on the basis of initial assessment of height, weight and Body Mass Index (BMI) $\left[<25 \mathrm{~kg} / \mathrm{m}^{2}\right]$. Further inclusion and exclusion criteria were checked. Then the data collection followed the same procedure as applicable for the study group.

Data collection was done under the supervision of respective supervisor/s. The data obtained were scored.

Statistical Analyses: statistical analyses were done using IBM SPSS version 20.0. Statistical analyses included descriptive statistics mean and standard deviations. Comparison of the two groups in terms of different variables was done using student's t-test. Predictive statistics were also done using logistic regression. 


\section{RESULTS}

The results of the following study have been shown in the following tables:

Table 1: Showing Differences between Obese and Non-Obese Groups In Terms Of Age, Height, Weight and BMI

\begin{tabular}{|l|l|l|l|l|l|}
\hline \multirow{2}{*}{ Variables } & Obese $\left(\mathbf{N}_{\mathbf{1}}=\mathbf{3 0}\right)$ & Non-obese $\left(\mathbf{N}_{\mathbf{2}}=\mathbf{3 0}\right)$ & & & \\
\cline { 2 - 7 } & Mean \pm SD & Mean \pm SD & t value & df & p value \\
\hline Age & $25.37 \pm 2.86$ & $26.1 \pm 2.86$ & 0.99 & 58 & 0.32 \\
\hline Height (m) & $1.63 \pm 0.08$ & $1.64 \pm 0.10$ & 0.23 & 58 & 0.82 \\
\hline Weight $(\mathbf{k g})$ & $73.95 \pm 9.34$ & $57.32 \pm 8.92$ & 7.05 & 58 & $0.00^{* *}$ \\
\hline BMI $\left(\mathbf{k g} / \mathbf{m}^{2}\right)$ & $27.82 \pm 2.26$ & $21.16 \pm 2.14$ & 11.72 & 58 & $0.00^{* *}$ \\
\hline
\end{tabular}

** significant at .01 level

Results of table -1 indicate that the obese and the non obese group differ significantly in terms of weight and BMI. The obese group had greater body weight as well as BMI.

Table 2: Showing Differences Between Obese And Non-Obese Groups In Terms Of ScoioDemographic Variables

\begin{tabular}{|c|c|c|c|c|c|c|}
\hline \multicolumn{2}{|l|}{ Variables } & $\begin{array}{l}\text { Obese } \\
\left(\mathbf{n}_{1}=30\right)\end{array}$ & $\begin{array}{l}\text { Non- } \\
\text { obese } \\
\left(\mathbf{n}_{2}=30\right)\end{array}$ & $\chi^{2}$ & df & $\begin{array}{l}\mathbf{p} \\
\text { value }\end{array}$ \\
\hline \multirow{2}{*}{ Sex } & Male & 15 (50\%) & $15(50 \%)$ & \multirow{2}{*}{0} & \multirow{2}{*}{1} & \multirow{2}{*}{1} \\
\hline & Female & $15(50 \%)$ & $15(50 \%)$ & & & \\
\hline \multirow{2}{*}{$\begin{array}{l}\text { Educational } \\
\text { qualification }\end{array}$} & $\begin{array}{l}\text { Graduation and } \\
\text { below }\end{array}$ & $13(43.3 \%)$ & $9(30 \%)$ & \multirow{2}{*}{1.15} & \multirow{2}{*}{1} & \multirow{2}{*}{0.28} \\
\hline & $\begin{array}{l}\text { Post graduation and } \\
\text { above }\end{array}$ & 17 (56.7\%) & $21(70 \%)$ & & & \\
\hline \multirow[b]{2}{*}{ Marital status } & Unmarried & $23(76.7 \%)$ & 27 (90\%) & \multirow[b]{2}{*}{1.92} & \multirow[b]{2}{*}{1} & \multirow[b]{2}{*}{0.17} \\
\hline & Married & $7(23.3 \%)$ & $3(10 \%)$ & & & \\
\hline \multirow{2}{*}{ Occupation } & Unemployed & $14(46.7 \%)$ & $18(60 \%)$ & \multirow{2}{*}{1.07} & \multirow{2}{*}{1} & \multirow{2}{*}{0.30} \\
\hline & Employed & $16(53.3 \%)$ & $12(40 \%)$ & & & \\
\hline \multirow[b]{2}{*}{ Family type } & Nuclear & 22 (73.3\%) & $24(80 \%)$ & \multirow[b]{2}{*}{0.37} & \multirow[b]{2}{*}{1} & \multirow[b]{2}{*}{0.54} \\
\hline & Other family & $8(26.7 \%)$ & $6(20 \%)$ & & & \\
\hline \multirow{2}{*}{$\begin{array}{l}\text { Family history of } \\
\text { endocrinological } \\
\text { disorder }\end{array}$} & $\begin{array}{l}\text { With family history } \\
\text { of endocrinological } \\
\text { disorder }\end{array}$ & 15 (50\%) & 7 (23.3\%) & \multirow[b]{2}{*}{4.59} & \multirow[b]{2}{*}{1} & \multirow[b]{2}{*}{$0.03 *$} \\
\hline & $\begin{array}{l}\text { Without family } \\
\text { history } \\
\text { endocrinological } \\
\text { disorder }\end{array}$ & 15 (50\%) & $\begin{array}{l}23 \\
(76.7 \%)\end{array}$ & & & \\
\hline
\end{tabular}

* significant at 0.05 level 
There exists a significant difference between obese and non-obese individuals with respect to family history of endocrinological disorder $\left(\chi^{2}=4.59 ; \mathrm{p}<.05\right)$. However, these two groups did not differ in terms of sex, educational qualification, marital status, occupation and family type (Table 2).

Table 3: Showing Comparison Between Obese And Non-Obese Group According To Personality Correlates (Neo Five Factors)

\begin{tabular}{|c|c|c|c|c|c|c|c|}
\hline \multirow{3}{*}{ Domains } & \multicolumn{4}{|c|}{ GROUP } & \multirow{3}{*}{$\mathbf{t}$} & \multirow{3}{*}{ df } & \multirow{3}{*}{ p value } \\
\hline & \multicolumn{2}{|c|}{ OBESE $\left(N_{1}=30\right)$} & \multicolumn{2}{|c|}{ NON-OBESE $\left(\mathrm{N}_{2}=30\right)$} & & & \\
\hline & Mean & SD & Mean & SD & & & \\
\hline Neuroticism & 21.93 & 6.79 & 22.53 & 8.69 & 0.30 & 58 & 0.77 \\
\hline Extraversion & 28.73 & 3.89 & 24.57 & 4.56 & 3.81 & 58 & $0.00 * *$ \\
\hline Openness & 26.13 & 5.56 & 30.17 & 5.25 & 2.89 & 58 & $0.01 * *$ \\
\hline Agreeableness & 27.07 & 4.43 & 26.37 & 4.21 & 0.63 & 58 & 0.53 \\
\hline Conscientiousness & 33.07 & 5.43 & 31.13 & 7.57 & 1.14 & 58 & 0.26 \\
\hline
\end{tabular}

** significant at 0.01 level

Findings reveal that obese group differs significantly from non-obese group in two domains of personality correlates measured through NEO Five Factor Inventory: Extraversion $(\mathrm{t}=3.81 ; \mathrm{p}<$ $0.01)$ and Openness $(t=2.89 ; \mathrm{p}=0.01)$. Since according to the inventory higher score indicates greater orientation in respective domain, greater mean score in obese group (Mean=28.73, $\mathrm{SD}=$ 3.89) than in the non-obese group (Mean= 24.57, $\mathrm{SD}=4.56$ ) with respect to the domain of 'Extraversion' implies that obese individuals tend to be more extravert, meaning more sociable, active, assertive, talkative, energetic, optimistic, cheerful. However, in case of 'Openness', the mean score in the obese group is found to be less (Mean= 26.13, $\mathrm{SD}=5.56$ ) as compared to the non-obese group (Mean= 30.17, $\mathrm{SD}=5.25$ ), implying that the former to be less open to experience, meaning poor in divergent thinking, active imagination, aesthetic sensitivity, less attentive to inner feelings, as compared to the latter (Table 3). 
Table 4: Showing Comparison Between Obese And Non-Obese Group According To SelfConcept

\begin{tabular}{|c|c|c|c|c|c|c|c|}
\hline \multirow{3}{*}{ Domains } & \multicolumn{4}{|l|}{ Group } & \multirow{3}{*}{$\begin{array}{l}\text { t } \\
\text { value }\end{array}$} & \multirow{3}{*}{ df } & \multirow{3}{*}{$\begin{array}{l}\mathbf{p} \\
\text { value }\end{array}$} \\
\hline & \multicolumn{2}{|c|}{ Obese $\left(\mathbf{N}_{1}=30\right)$} & \multicolumn{2}{|c|}{$\begin{array}{l}\text { Non- } \\
\text { obese }\left(\mathbf{N}_{2}=30\right)\end{array}$} & & & \\
\hline & Mean & SD & Mean & SD & & & \\
\hline Social self concept & 20.40 & 3.14 & 19.17 & 3.05 & 1.54 & 58 & 0.13 \\
\hline Emotional self concept & 26.17 & 3.26 & 29.67 & 6.23 & 2.73 & 58 & $0.01 * *$ \\
\hline Physical self concept & 10.13 & 2.80 & 9.83 & 1.93 & 0.48 & 58 & 0.63 \\
\hline Cognitive self concept & 17.43 & 2.98 & 15.50 & 3.47 & 2.31 & 58 & $0.02 *$ \\
\hline Aesthetic self concept & 5.17 & 2.48 & 4.43 & 2.61 & 1.12 & 58 & 0.27 \\
\hline Political self concept & 17.27 & 3.22 & 15.40 & 3.01 & 2.32 & 58 & $0.02 *$ \\
\hline Job related self concept & 23.13 & 3.39 & 20.57 & 3.92 & 2.71 & 58 & 0.01** \\
\hline Self confidence & 10.30 & 2.10 & 10.23 & 2.57 & 0.11 & 58 & 0.91 \\
\hline $\begin{array}{l}\text { Self concept related to } \\
\text { beliefs and traditions }\end{array}$ & 13.03 & 2.33 & 15.03 & 2.20 & 3.42 & 58 & $0.00 * *$ \\
\hline $\begin{array}{l}\text { Self concept related to } \\
\text { personality traits }\end{array}$ & 14.00 & 2.36 & 13.00 & 2.82 & 1.49 & 58 & 0.14 \\
\hline Composite self concept & 157.03 & 15.90 & 152.83 & 14.72 & 1.06 & 58 & 0.29 \\
\hline
\end{tabular}

Table 4 shows the comparison between obese and non-obese group according to self-concept. It is observed that obese and non-obese group differ significantly with respect to 'Emotional Self Concept' $(t=2.73 ; p=0.01)$, 'Cognitive Self-Concept' $(t=2.31 ; p<0.05)$, 'Political SelfConcept' ( $t=2.32 ; \mathrm{p}<0.05)$, 'Job-related Self-Concept' $(\mathrm{t}=2.71 ; \mathrm{p}=0.01)$ and 'Self concept related to beliefs and traditions' $(\mathrm{t}=3.42 ; \mathrm{p}<0.01)$. As higher score in SCI is indicative of good self-concept in respective domains, lesser mean in 'Emotional Self-Concept'(Mean= 26.17; SD =3.26) and 'Self-concept related to beliefs and tradition' (Mean= 13.03; $\mathrm{SD}=2.33$ ) in obese group than those of in non-obese group $(\mathrm{Mean}=29.67 ; \mathrm{SD}=6.23$ and Mean=15.03; $\mathrm{SD}=2.20$ respectively), indicates that obese group tends to be poorer than the non-obese group in these domains. On the other hand, greater mean in the domains of 'Cognitive Self-Concept' (Mean= 17.43; SD= 2.98), 'Political Self-Concept' (Mean= 17.27; SD= 3.22) and 'Job Related SelfConcept' (Mean= 23.13; SD= 3.39) than those of in non-obese group (Mean=15.50, SD= 3.47; Mean= 15.40, $\mathrm{SD}=3.01$; Mean= 20.57, $\mathrm{SD}=3.92$ respectively) implies better self-concept in obese individuals as compared to the non-obese ones in these domains (Table 4). 
Table- 5 Showing Various Personality Traits As Predictors Of Obesity (Regression Coefficient) $(N=60)$

\begin{tabular}{|l|l|l|l|}
\hline PREDICTOR VARIABLE & STANDARDIZED BETA & t & p-value \\
\hline neuroticism & .040 & .324 & .747 \\
\hline extraversion & $\mathbf{. 2 6 4}$ & $\mathbf{1 . 9 8 3}$ & $\mathbf{. 0 4 2}$ \\
\hline openness & $\mathbf{- . 3 4 5}$ & $\mathbf{- 2 . 5 2 5}$ & $\mathbf{. 0 1 5 *}$ \\
\hline agreeableness & -.075 & -.575 & .567 \\
\hline conscientiousness & -.001 & -.009 & .993 \\
\hline
\end{tabular}

*Significant at the 0.05 level (2-tailed)

**Significant at the 0.01 level (2-tailed)

$\mathrm{R}$ square $=0.222, \mathrm{~F}(5,54)=3.086(\mathrm{p}<0.05)$

Adjusted R square $=0.150$

Results indicate type of personality significantly predicted body mass index (Obesity) $\mathrm{t}(60)=$ $4.174(<0.001)$. The major predictors were found to be extraversion and openness (Table 5).

Table-6 Showing Various Domains Of Self Concept As Predictors Of Obesity (Regression Coefficient)

\begin{tabular}{|l|l|l|l|}
\hline $\begin{array}{l}\text { PREDICTOR } \\
\text { VARIABLE }\end{array}$ & $\begin{array}{l}\text { STANDARDIZED } \\
\text { BETA }\end{array}$ & $\mathbf{t}$ & p-value \\
\hline Social self concept & -.686 & -2.198 & $\mathbf{. 0 3} *$ \\
\hline $\begin{array}{l}\text { Emotional self } \\
\text { concept }\end{array}$ & -1.013 & -2.964 & $\mathbf{. 0 0 5}{ }^{* *}$ \\
\hline Physical self concept & -.656 & -3.042 & $\mathbf{. 0 0 4} *$ \\
\hline $\begin{array}{l}\text { Cognitive self } \\
\text { concept }\end{array}$ & -.379 & -1.465 & $\mathbf{. 0 4 9}$ \\
\hline $\begin{array}{l}\text { Aesthetic self } \\
\text { concept }\end{array}$ & -.672 & -2.027 & .088 \\
\hline Political self concept & -.364 & -2.247 & $\mathbf{. 0 4 8}$ \\
\hline Self confidence & -.616 & -3.044 & $\mathbf{. 0 2 9}$ \\
\hline $\begin{array}{l}\text { Self concept related } \\
\text { to beliefs and } \\
\text { traditions }\end{array}$ & 2.505 & 2.808 & $\mathbf{. 0 0 4}$ \\
\hline $\begin{array}{l}\text { Self concept related } \\
\text { to personality traits }\end{array}$ & .264 & 1.983 & .078 \\
\hline $\begin{array}{l}\text { Composite self } \\
\text { concept }\end{array}$ & -.345 & -2.525 & $\mathbf{. 0 0 7 *}$ \\
\hline
\end{tabular}

*Significant at the 0.05 level (2-tailed)

**Significant at the 0.01 level (2-tailed)

$\mathrm{R}$ square $=0.290, \mathrm{~F}(10,49)=2.003 *(\mathrm{p}<0.05)$

Adjusted R square $=0.145$ 
Results indicate self concept significantly predicted body mass index (Obesity) t (60) $=4.763$ $(<0.001)$. The major predictors related to self concept were found to be social, emotional, physical, cognitive, political, self confidence, self concept related to beliefs and traditions and composite self concept.

\section{DISCUSSION}

According to the objectives of the present study, statistical analysis of the data attempted to probe into the fact whether there exits any significant difference between obese and non-obese groups and to find out psychological predictors of obesity with respect to the domains of personality traits and self-concept. Some findings of the study have brought out certain basic differences with respect to selected variables amongst the two groups.

\section{Obesity and Sociodemographic Factors:}

In the present study, the total sample comprised of 60 individuals within the age group 21- 32 years (mean=25.73 \pm 2.86 ) were classified into obese and non-obese groups on the basis of measures of BMI. As per the objective (to compare between obese and non-obese adults), the groups were matched in terms of age and sex. Findings of comparison between the two groups along other sociodemographic variables viz., education, occupation, marital status, family types etc. denote no significant difference.

In addition, the present study shows significant difference between obese and non-obese individuals with respect to family history of endocrinological disorders which is in accordance with earlier findings and provides support in favour of genetic inheritance of and predisposition to obesity (Bouchard, 1994; Crossman, Sullivan \& Benin, 2006).

\section{Obesity and Personality:}

Personality traits are consistently associated with the controllable behaviours that led to obesity (Provencher et al., 2008) and personality has an effect on adiposity even after controlling for known demographic and genetic influences (Terracciano et al., 2009).

Present study findings imply that obese individuals tend to be more extravert but less open as compared to their non-obese counterparts; these two traits of extraversion and openness have been found to be the major predictors of obesity. This means that obese individuals tend to be more sociable, active, assertive, talkative, energetic, optimistic and cheerful. This finding contrasts the proposition of lower extraversion related to higher obesity (Courneya \& Hellsten, 1998; Rhodes,Courneya\& Jones, 2003; Elfhag\& Morey, 2008). However, obese individuals tend to be less open to experience; poor in divergent thinking, active imagination and aesthetic sensitivity; less attentive to inner feelings; conventional, unadventurous and conforming as compared to non-obese individuals (Day et al., 2005). This finding may indicate their surface level information processing, in turn corroborating with the finding of emotional empowerment of the cognitive aspects of self-concept. Moreover, greater extraversion coexisting with lesser 
tendency of openness to experience may provide further explanation for their poor self-concept related to beliefs and traditions, questioning their core beliefs about self, culture and traditions and may thereby lead them to follow the mainstream flow of social and cultural changes without being mindful about how self is related to external world.

Moreover, majority findings from existing literature suggest Conscientiousness to be inversely associated with obesity. In contrast, neither the comparison between groups nor the regression analysis as found in the present study would indicate any such statistically significant findings.

Hence, it may be suggested that particular dimensions of personality may contribute, either directly or through their association with other psychological factors, to a better understanding of weight gain issue in obesity (Provencher et al., 2008).

\section{Obesity and Self-Concept:}

The self-concept is an organized, consistent conceptual gestalt composed of perceptions of the characteristics of "I" or "Me" to others and to various aspects of life, together with the values attached to these perceptions (Rogers, 1959). The current findings indicate that obese individuals have significantly poorer Emotional Self-concept as compared to the non-obese ones which may signify obese individuals' vulnerability to develop affective disturbances, dysphoria and even depression (Luppino et al., 2010). Poor 'self-concept related to beliefs and traditions 'of obese individuals in comparison with their non-obese counterparts, may imply dysfunctional core of the self concept in association with social and cultural aspects of self as governed by contextual experiences (Hilbert et al., 2013). In fact, just being associated with someone who is overweight can lead to negative evaluations (Hebl \& Mannix, 2003). As such, body weight contributes to how we understand ourselves, how we see others, and how others see us.

Although the two groups have shown to differ significantly in terms of 'Cognitive self-concept', the obese group scores higher in this dimension than the non-obese group, thus implying their potential ability to process self related information and interpretations drawn from environmental cues in an effective and more adaptive manner. This may serve as a good prognostic indicator in case of obesity related interventions.

In addition, this finding when considered together with poor emotional self-concept in obese individuals may provide us with the explanation how thinking and behaviour are distorted to be congruent with emotional states (Linehan, 1993).

The overall obese group is also found to better in 'Political Self-Concept' and 'Job Related SelfConcept' as compared to their non-obese counterparts. The results of predictive statistics indicated social, emotional, physical, cognitive, political, self confidence, self concept related to beliefs and traditions and composite self concept to be major predictors of obesity. This bears a connotation for the sedentary life style, spending greater time in workplace which mostly involves less physical activity in contrast with greater availability of high calorie food. Moreover, social, cultural traditions are by no means fragile issues. Those culminate propensity 
to adhere to the traditional life style practices, often results in weight gain and obesity. In contrary, our experiences of regular social affairs and the narratives patients give at the time of explaining their problems in the clinic, probe us to report the contradiction between their access of weight loss interventions and continuing with the same life style pattern prevailed before they opted intervention. However, available literature would not provide any direction in explaining these aspects. These domains, thus, need further exploration.

Therefore, we can conclude on the note that for obese individuals, the core of the self and the cognitive understanding about the self system in relation with society, culture and traditions are much governed by the usual customs prevail in society for generations. Despite having the potential for cognitive flexibility and adequate social skills, their self-management skills are lacking. So they cannot make effective use of these available potentialities and are vulnerable to emotional and behavioural difficulties. These two aspects together prompt such a lifestyle that is potent enough to give birth to physical problem like obesity. Analyses of the results clearly indicate that personality traits and self-concept are significant predictors of obesity. The detail narration of the results may serve as a worthy database in weight management programme for obese individuals.

However, the study is not free of limitations. The present sample was small in size. With larger samples, more subtle changes in mean scores can be detected over time leading to more precise comparison between obese and non-obese individuals. In addition, here the individuals are broadly assigned into two groups, namely obese and non-obese, including overweight in the nonobese group and BMI was taken as the only demarcation between the two groups. Classifying overweight individuals in a separate category and using other parameters for diagnosing obesity cases might have led towards more precision.

Acknowledging these limitations, it can be highlighted from the findings that the present study would aid the treatment process of obesity and help health professionals to plan intervention incorporating the bio-psycho-social aspects, so that complexities of the obesity management can be effectively facilitated.

\section{REFERENCES}

Asia Pacific Cohort Studies, Collaboration, (2007). The burden of overweight and obesity in the Asia-Pacific region. Obesity Reviews, 8, 191-196.

Booth-Kewley, S., \& Vickers, R.R. (1994).Associations between major domains of personality and health behavior. Journal of Personality, 62, 281-298.

Bouchard, C. (1994). The Genetics of Obesity: CRC Press.

Brummett, B.H., Babyak, M.A., Williams, R.B., Barefoot, J.C., Costa, P.T., \& Siegler, I.C. (2006). NEO personality domains and gender predict levels and trends in body mass index over 14 years during midlife . Journal of Research in Personality, 40(3), 222-236.

Centers for Disease Control, (CDC, 2006). Overweight and obesity: Contributing factors. Retrieved from http://www.cdc.gov/nccdphp/dnpa/obesity/ contributing_factors.htm.

Cooley, C. H. (1902). Human nature and the social order. New York: Charles Scribner's Sons. 
Costa, P.T. \& McCreae, R.R. (1985).The NEO Personality Inventory. Odessa, FL: Psychological Assessment Resources. In Pennington, D., Essential Personality, 149-162. New York, NY: Oxford University Press Inc.

Courneya, K.S., \& Hellsten, L.A.M. (1998). Personality, correlates of exercise behavior, motives, barriers and preferences: An application of the five-factor model. Personality and Individual Differences, 24(5), 625-633.

Crossman,A., Sullivan, D.A.,\& Benin, M. (2006). The family environment and American adolescents' risk of obesity as young adults. Social Science \& Medicine, 63(9), 22552267.

Day, H.R., Schaie, K.W. \& Sherry L. Willis (2005).Correlations between Personality and Body Mass Index in a Cross-Sectional Sample of the Seattle Longitudinal Study. Retrieved from: www.nspb.net/index.php/nspb/article/view/204/294

Digman, J.M. (1990). Personality Structure: emergence of the five factor model. In M.R. Rosenweig and L.W. Porter (Eds), Annual Review of Psychology, 41 (pp.417-40). Palo Alto, CA: Annual Reviews Inc., New York, NY: Oxford University Press Inc.

Elfhag,K. \& Morey, L. (2008).Personality traits and eating behavior in the obese: Poor selfcontrol in emotional and external eating but personality assets in restrained eating. Eating Behaviors, 9(3), 285-293.

Goldberg D. P, \&Miller V. E. (1979).A scaled version of the General Health Questionnaire. Psychological Medicine,9, 139-46.

Haslam, D.W. \& James, W.P. (2005).Obesity. Lancet, 1, 366(9492), 1197-209.

Hebl, M.R., \& Mannix, L.M. (2003). The weight of obesity in evaluating others: A mere proximity effect. Personality and Social Psychology Bulletin, 29, 28-38.

Hilbert, A., Braehler, E., Haeuser, W.,\& Zenger, M. (2013). Weight bias internalization, core self-evaluation, and health in overweight and obese persons. Obesity.doi: 10.1002/oby.20561.

Hong, Y. (2013).The Relationship between Students’ Conscientiousness Level and their Healthy Eating Behavior. Retrieved from: www.psych.umn.edu/sentience.

http://www.who.int/dietphysicalactivity/publications/facts/obesity/en/.http://www.who.in t/nmh/publications/ncd_report2010/en/index.html

Kakizaki, M., Kuriyama,S., Sato, Y., Shimazu, T., Matsuda-Ohmori,K., Nakaya, N., Fukao, A., Fukudo,S., \&Tsuji, I. (2008). Personality and body mass index: A cross-sectional analysis from the Miyagi Cohort Study. Journal of Psychosomatic Research, 64(1),71-80. Lau, P., Cheung, M., \& Ransdell, L. (2008).A structural equation model of the relationship between body perception and self- esteem: Global physical self-concept as the mediator. Psychology of Sport and Exercise, 9(4), 493-509.

Linehan, M. (1993). Skills Training manual for Treating Borderline Personality Disorder. 63-64

Luppino, F.S., De Wit, L.M., Bouvy, P.F., Stijnen, T., Cuijpers, P., \& Penninx B.W. (2010). Overweight, obesity, and depression: A systematic review and meta-analysis of longitudinal studies. Archives of General Psychiatry,67(3), 220-229.

Magee, C. \&Heaven, P. (2011.)Big-Five personality factors, obesity and 2-year weight gain in Australian adults. Journal of Research in Personality,45(3), 332-335.

McCrae, R.R. \&Costa, P.T. (1989). The structure of interpersonal traits: Wiggins' circumflex and the five factor model. Journal of Personality and Social Psychology, 56, 586-595. In Pennington, D., Essential Personality, 149-162, New York, NY: Oxford University Press Inc. 
McCrae, R.R. \& Costa, P.T. (1991). NEO-PI-R Professional Manual. Psychological Assessment Resources, Inc.

McCrae, R.R.\& Costa, P.T. (1990). Personality in Adulthood. New York: Guilford Press. In Pennington, D., Essential Personality, 149-162, New York, NY: Oxford University Press Inc.

Misra, A., Chowbey, P., Makkar, B.M., Vikram, N.K., Wasir, J.S., \& Chadha D. (2009).Consensus statement for diagnosis of obesity, abdominal obesity and the metabolic syndrome for Asian Indians and recommendations for physical activity, medical and surgical management. Journal of the Association of Physicians of India,57, 163-70.

Provencher, V., Bégin, C., Gagnon-Girouard, M.P., Tremblay, A., Boivin, S., \&Lemieux S. (2008). Personality traits in overweight and obese women: Associations with BMI and eating behaviors. Eating Behaviors, 9, 294-302.

Rashmi\&Jaswal, S. (2010). Self-Concept of Obese and Non-Obese Urban Teenagers. Journal of Clinical Psychology, 1 (2), 73-78.

Rhodes, R.E., Courneya, K.S., \&Jones, L.W. (2004). Personality and social cognitive influences on exercise behavior: Adding the activity trait to the theory of planned behavior. Journal of Sport \& Exercise Psychology, 5, 243-254.

Roehling, M.V., Roehling, P.V, \&Odland, L.M. (2008).Investigating the validity of stereotypes about overweight employees: The relationship between body weight and normal personality traits. Group and Organization Management,33, 392-424.

Rogers, C.R. (1959). A theory of therapy, personality, and interpersonal relationships. In S. Koch (Ed.), Psychology: A Study of a Science, vol. III (pp. 184-256). New York: McGraw Hill.

Rosenberg, M. (1979).Conceiving the self. Malabar, FL: Robert Krieger Publishing Company.

Shah, B. (1986).Manual for Self-concept Inventory (Adults). Agra Psychological Research Cell

Terracciano, A., Sutin, A.R., McCrae, R.R., Deiana, B., Ferrucci, L., Schlessinger, D., Uda, M., \&Costa, P.T. (2009).Facets of personality linked to underweight and overweight. Psychosomatic Medicine, 71, 682-689.

Valenti, M.P., Omizo, M.M., \&Mehl-Madrona, L. (2011). Personality and Obese Body Mass Index.The New School Psychology Bulletin, 9(1), 34-38.

Wakslak, C. J., Shiri, N., \&NiraLiberman (2008), "Representations of the Self in the Near and Distant Future", Journal of Personality and Social Psychology, 95, 757-773.

Witherspoon, D., Latta, L., Wang, Y.,\& Black, M.M. (2013). Do Depression, Self-esteem, Bodyesteem, and Eating Attitudes Vary by BMI Among African American Adolescents? Journal of Pediatric Psychology, [Epub ahead of print] PMID:23912163

World Health Organization, (2010)."Global Strategy on Diet, Physical Activity and Health. Retrieved from 